\title{
Monitoring and Controlling a Construction Project in the Classroom
}

\section{Col. Brad Wambeke P.E., United States Military Academy}

Colonel Brad Wambeke is the Civil Engineering Division Director at the U.S. Military Academy, West Point, NY. He received his B.S. from South Dakota State University; M.S. from the University of Minnesota; and Ph.D. from North Carolina State University. He is a member of ASEE and is a registered Professional Engineer in Missouri. His primary research interests include construction engineering, lean construction, and engineering education.

\section{Major Todd Mainwaring, United States Military Academy}

Major Todd Mainwaring is a junior rotating faculty member. Todd is a 2007 graduate of the United States Military Academy. He has earned two Masters of Science from Stanford University: one in Civil Engineering (Sustainable Design and Construction) and another in Management Science. His areas of interest include energy efficient building design, industrialized construction and life cycle assessment. 


\section{Monitoring and Controlling a Construction Project in the Classroom}

The planning phase of construction is relatively easy to implement in a classroom setting. Exercises that demonstrate and assess estimating and scheduling techniques are common. Students can conduct material take-offs, labor productivity estimates, build network diagrams and Gantt charts, while using plans and specifications from real-world projects. The execution phase, however, is far more difficult to simulate. The classroom is constrained by time and space which often prohibits students from executing, monitoring, and controlling their plan.

CE450: Construction Management, taught in the Department of Civil and Mechanical Engineering at West Point, uses Project Imperium to provide students with a simulated construction experience in which they can plan, execute, monitor, and control a project. In Project Imperium, instead of using real plans and real materials, students employ K'NEX rods and connectors to build a structure, such as a two-story club house or a bridge. Material, labor and equipment prices and rates are provided to teams of four students who are responsible for placing a competitive bid (price and duration) for the project. With this information, teams develop a baseline from which they apply earned value analysis to monitor their performance. Teams are then expected to build the clubhouse in six "months" of construction - each month is 10 minutes long. During this time, students are monitoring progress using metrics which begin to shape decisions in future months. With the assistance of a spreadsheet model, students can visually see trends in costs and schedule which help them make decisions to correct their trajectory. The model is composed of management "levers" the students can pull. The project manager can crash the project by authorizing overtime or adding additional workers. On the other hand, they can also cut costs by selecting cheaper labor and poor-quality material. Of course, there are inherent risks in these cost-cutting measures: too many "cheap" choices can lead to litigation from the owner. It is the repercussions of these decisions which Imperium and the model provides. Immediately, a student can see the outcome of a construction management choice. Cost-cutting decisions result in an increase in the "litigation potential" indicator on the student's dashboard. Crashing choices results in a drop in projected profit, but also a potential to decrease total project duration. This visualization of cause and effect improves decision making skills.

Future construction managers should be able to monitor progress, assess data, and make an informed decision to control the outcome of a project. Many gain this skill from actual work experience; perhaps, it is possible to gain it in the classroom. Creating this management experience in the classroom ensures our students can immediately add value to the projects they'll manage after they graduate. 


\section{Project Imperium Description}

Outside of on-the-job experience, developing the skills and intuition to monitor and control a project can be challenging. In order to ensure inexperienced project managers possess these skills upon graduation, one must simulate those experiences in the classroom. The authors achieved this simulated effect through a construction exercise called Imperium. This name is intentional: "imperium" is Latin for "control." Project controls — or management - is the primary objective of the in-class exercise. The authors strived to maintain a "true-to-life" experience. While the structure is composed entirely of KNEX, a popular children's toy, the rules, processes and scenario are very realistic.

First students were organized into teams and a project manager was selected. This project manager is not a permanent position; each student will spend a portion of Project Imperium in this role of responsibility. The teams are challenged with the following scenario:

"The United States Military Academy is seeking to rebuild their golf course club house. Leadership wants this new structure to be a large, inviting building that serves golfers as well as large events. The Academy already has detailed plans and intends to put the project up for bid. Figure 1 is a screenshot from the building information model (BIM) for the structure. They've hired an owner's representative from Vitruvius Consulting Group to act on their behalf throughout the process. They call the project: Imperium. You work at a local construction firm that is interested in going after the project. The owner selected a Design-Bid-Build project delivery method with a lump sum contract.

Throughout this process you will create an estimate and schedule which will result in a bid package. If awarded, you will then execute construction, but more importantly, you will monitor and control this project. You will be faced with management decisionsacts of nature, delayed materials, unforeseen site conditions - and you will be required to make real-time decisions using performance data at hand."

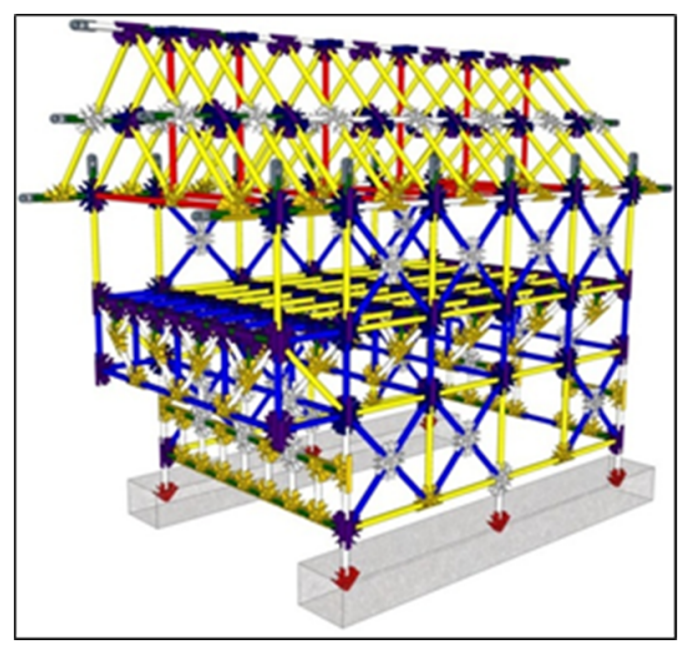

Figure 1: Project Imperium Building Information Model 
In the first stage of the project, teams must develop a rough-order-of-magnitude estimate to determine if the project is worth pursuing. They are reminded that developing a detailed estimate and schedule requires resources; therefore, they must determine the general feasibility and profitability of a project. With only a set of plans and historical performance data, each team creates their initial estimates. There are no models of the club house in the room. Students must conduct material take-offs using only engineering drawings and a Google Sketchup building information model (Figure 1) provided to them. While the KNEX structure is much less complex than even the simplest real-world projects, this experience of navigating drawings and models is revealing as many students struggle to accurately estimate the number and type of KNEX pieces.

Teams must calculate an initial estimate of the direct costs. Each KNEX part has a price associated with it; once the material take-off is complete, teams can calculate their material costs. Teams determine the cost of labor and equipment using historical data. Instructors in the course have run similar exercises to this in the past and have several years of teams' total construction times (in minutes). These times are averaged and sorted in to "trained," "proficient" and "untrained" times. Students simply select the time that fits their perceived skill level at the point. At this early stage, students must assess their proficiency at building with this material and structure type. Interestingly, very few have ever used this product, but almost all select "trained" times - the most aggressive time estimates. At this early stage of the project, students are told that the CEO of their construction firm will use this initial estimate to determine if they'll pursue the project. Many inexperienced engineers, early in their careers, learn not to make promises they cannot keep, yet our students consistently present the boss - the instructor - with the most aggressive estimated construction times instead of more conservative ones.

Finally, teams must roughly estimate the amount of equipment time this project will require. Much more rigor will be put into this decision later, but at this point, teams rely, again, on historical data. It is important to note, the equipment - a KNEX crane - is the most expensive hourly cost on the project. Contrary to the aggressive construction times, this equipment cost estimate is often overestimated greatly inflating this initial estimate.

Teams submit their initial estimates to their instructor. Any material errors are highlighted in this submission. Instructors provide feedback to teams that might have been overzealous in their construction and equipment usage times. Regardless, all teams are given the green light to continue developing more detailed estimates and a construction schedule.

Aside from actually constructing the club house, developing the schedule is the most significant endeavor. Teams are primed with the following information: a scheduling team conducted a work breakdown structure and determined the tasks to be completed, but they have not determined the sequence or duration of activities. Essentially, teams are provided a list (Table 1) of scrambled tasks and must determine when they happen and for how long. There are only a few activities where the activity duration is provided. This leads to some divergences among the teams. Some are very cautious and conservatively all schedule tasks sequentially. Other teams, noting the time-savings of concurrently executing unrelated tasks, stack unrelated activities in one time period. 
Table 1: Project Imperium Activities

\begin{tabular}{|c|c|l|c|}
\hline ID & Activity & Precedence & Duration \\
\hline & Complete $2^{\text {nd }}$ Floor & & \\
\hline & Prefab Roof Trusses & & \\
\hline & Mobilize / Site Prep & & $1 \mathrm{~min}$ \\
\hline & Construct $2^{\text {nd }}$ Floor Walls & & \\
\hline & Install Roof Trusses & & \\
\hline & Complete Roof & & \\
\hline & Place precast footers & & \\
\hline & Prefab $2^{\text {nd }}$ Floor Trusses & & \\
\hline & Demobilize / Closeout & & $1 \mathrm{~min}$ \\
\hline & Construct $1^{\text {st }}$ Floor Walls & & \\
\hline & Excavate & & $2 \mathrm{~min}$ \\
\hline & Install $2^{\text {nd }}$ Floor Trusses & & \\
\hline
\end{tabular}

Regardless of their scheduling decisions, teams must first determine activity durations. This is a point of artificiality in the exercise. While we are using a toy product as our building material, there is no RSMeans or productivity data to calculate construction times. Therefore, teams must actually rehearse each activity. This practice period serves two purposes. First, it yields very accurate construction times which can fill the network diagram. Second, it forces students to get their hands on the KNEX and become familiar with how they work. With activity durations and logical relationships, a network diagram can be generated. Conducting a forward pass, students determine their project duration; their backward pass reveals the critical path and total float available. Transferring this information onto a Gantt Chart makes their plan more user-friendly and creates a product teams can use to measure and track performance during construction.

Meanwhile, teams are refining their estimates. Direct costs are now determined by construction activity. Teams must allocate materials to specific tasks and determine whether those activities require a crane. Crane specifications force this decision: 1) a crane must be used anytime an assembly of K'NEX components measuring greater than a "yellow-by-yellow-by-yellow cube with connectors" in any direction is moved, 2) the crane's lifting capacity is 175 grams. Here, we see another judgement building moment. Seen in isolation, many teams will assume they have to rent a crane multiple times to support separate construction activities. However, transportation times to and from the equipment storage yard, a room on a separate floor of the building, must be considered in the crane rental cost. Many teams do not see the inefficiency of renting a crane multiple times, as opposed to scheduling several activities that require a crane to occur close together and thus minimizing the transportation costs.

These material, equipment and labor costs per activity are recorded and feed an overall bid worksheet. Once total direct costs are determined from the activity worksheets and Gantt Chart, teams must determine their indirect costs. The cost to secure bonds and pay overhead is provided as $10 \%$ of their direct costs, but teams must determine their own profit margin. If accepted this bid becomes the value of the lump sum contract, so one might assume students would inflate their profit margins to give them plenty of room to make a hefty profit. The constraints of the 
exercise prevent this: the lowest responsible and responsive bid is award maximum points on this graded event and all others are proportionally scaled off of this "winning" bid. Since, in real-life, only one contractor would win the project, this rule seeks to reward the most competitive bid while still being able to award the project to all teams so they can all continue the academic exercise.

Once the contract is awarded, teams must develop a schedule of values to determine how they will be paid. This lays the baseline against which their performance will be evaluated during the exercise. Using the activity sheets (direct costs) and the Gantt Chart, teams determine not only how much tasks cost, but when those costs occur. This Schedule of Values chart, or planned value, serves as an agreement between the contractor teams and the owner regarding how much value will be created over the 6 simulated months of construction. This feeds the dashboard.

\section{Construction Manager's Dashboard}

The primary tool to assist with monitoring and controlling the project in this exercise is the construction manager's dashboard. Being able to "see" second and third order effects of decisions normally takes years of experience in project management. This dashboard, a robust spreadsheet model, seeks to provide that "vision" that these aspiring managers lack.

\section{Input}

The interface begins with students loading their plans into the model. Up to this point, each team has developed their Gantt Charts, cost estimates and schedule of values by hand. Each of these interim submissions are graded and the instructor's feedback is incorporated into the final bid, which is also graded. This ensures that the final hardcopy products are sound, and results in a signed contract between each team and the owner (the instructor). From this official document, teams load the contract price and project duration that the owner agreed to. The predicted profit margin, direct and indirect costs and the schedule of values (planned values) are input as well. This is essential to implementing earned value analysis (EVA). These planned values, the duration and cost, form the foundation of all EVA metrics that the dashboard will display as teams progress through the construction phase. An example is shown below in Figure 2.

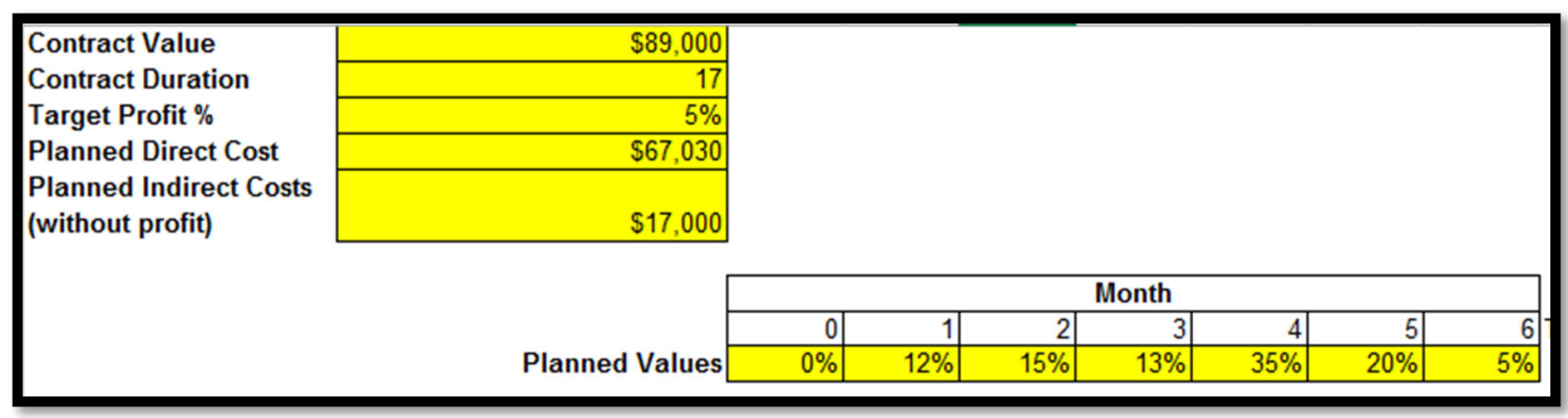

Figure 2: Example of Team Input at the start of Project Imperium 


\section{Dashboard}

These inputs create the baseline display, referred to as the dashboard and shown in Figure 3, the students will use to manage their projects. First, the spreadsheet formulas auto-calculate two things: the planned cash flows and the planned value curve of the EVA chart. These serve as baselines against which the teams will evaluate their actual performance.

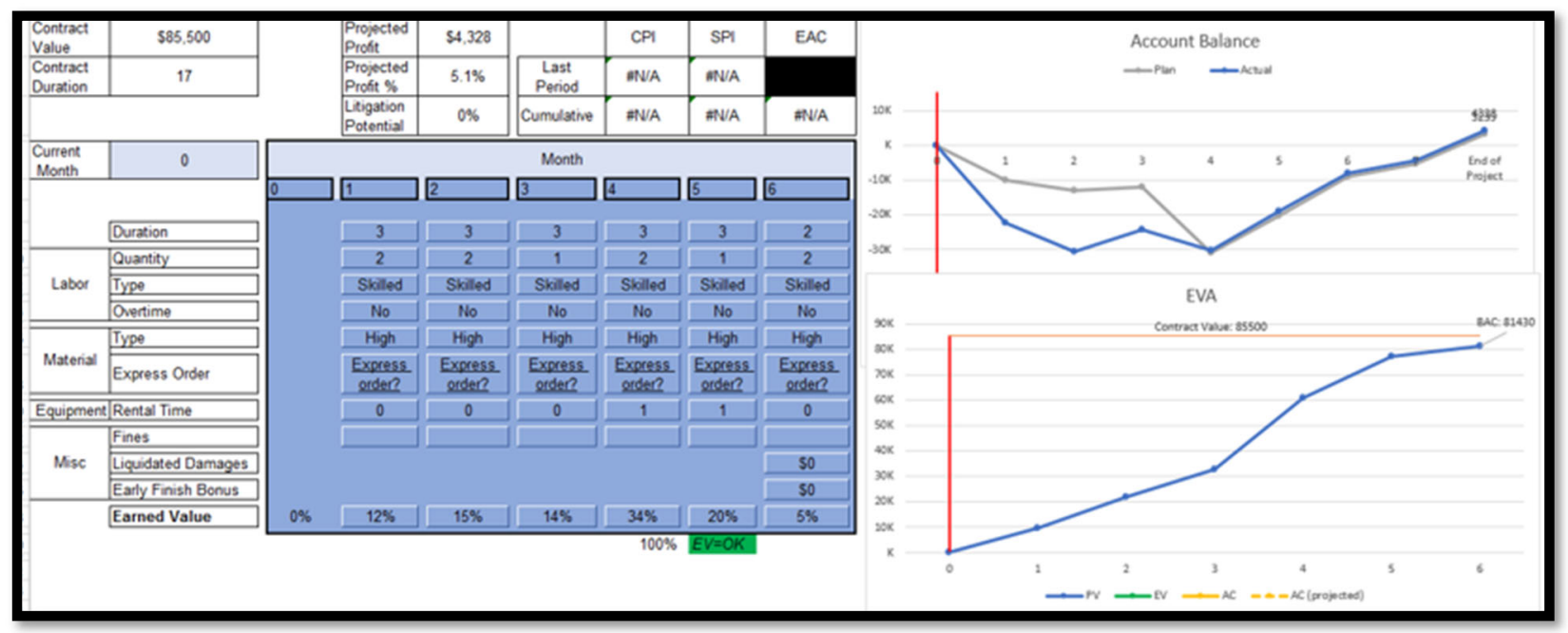

Figure 3: Project Imperium Dashboard

In the top left of the dashboard, the administrative information, such as the contract value and duration, are displayed. Any cells labeled in white are populated from calculations or inputs from other spreadsheets in the workbook; they are locked, and the students cannot inadvertently change them. Essentially, these are the outputs that will inform the project manager's decisions. Cells colored in blue, represent a management decision that teams must make as the project progresses. It is difficult to portray the passage of time in this exercise. Because the project is not continuous in real-time, students attend class and perform work on their projects every other day, the students must manually update what moment in time they are in. As mentioned earlier, each "month" is actually 10 minutes. Beneath the administrative information, students must update the "Current Month" which will highlight that month's decisions on the dashboard and also update all EVA calculations so that they incorporate all past month's decisions and outcomes. Before the project begins, this cell, of course, is " 0. ."

\section{Levers}

There are two primary functions this tool provides inexperienced construction managers: there is a menu of options they can choose to affect the outcome of the project, but also ramifications of those choices can be seen beforehand. These "levers" are pulled in between each month of construction and the implications of those decisions are displayed graphically on the "Account Balance" and numerically in the "Projected Profit" and "Litigation Potential." These two outputs reveal the complexity of every decision. Certain levers might save money or time, but they also 
might reduce the quality of work, and therefore expose the contractor to litigation risk. The menu of inputs, or levers, available to the managers are:

a) Duration: represents the number of minutes the team actually worked in that month. In all months, except the month they finish, this will be the maximum days in that month (10). For example, for every full month of construction, the CM would input " 10 ," but in the month they finish work, they would put in something less than 10 (" 3 " perhaps, if they finished by the third minute). This number is important because it drives labor costs, indirect costs and might result in an early finish bonus or liquidated damages.

b) Labor Size: CMs select the number of laborers they will have physically working on the project that month. For future months, this is how many people you plan to have working.

c) Labor Type: CMs can hire SKILLED or UNSKILLED labor. Skilled labor delivers high quality, but costs more. Unskilled labor may save money but deliver lower quality work.

d) Overtime: there are times when crashing the project may make sense. This feature allows CMs to extend the CURRENT crew for 2 more minutes of work at $1.5 \mathrm{x}$ the cost. They either choose YES or NO.

e) Material Type: On real-world projects contractors can often select suppliers from vendors they choose. There may be times when a manager decides to reduce costs by choosing lower quality materials. CMs must be cautious, as this could decrease the quality of your project. Choices are HIGH or LOW.

f) Express Order Material: if a team outpaces their materials on hand and wants to continue work (and earn more value!), it may make sense to EXPRESS ORDER materials from future months. This button (a hyperlink) leads the CM to another worksheet where they input the quantities you want. They will be charged at the High-quality material rate as well as a $50 \%$ mark-up for the expedited delivery.

g) Equipment Rental Time: CMs input the number of minutes they plan to (or used) the crane. They must manage the crane closely, this is the most expensive line item in the budget.

h) Fines: teams can incur fines for misusing the crane, safety violations, material yard overflow. They input the cost of those fines directly.

Teams have an initial baseline plan for all of these decisions for every month they plan to construct, but as the project progresses, they will monitor performance and may be forced to change those original choices in order to deliver a quality project, on schedule, under budget.

In pulling all of levers, CMs can visualize the effects of these decisions on the "Scoreboard." At the top of the screen, the supporting worksheets perform all of the calculations to provide the aspiring manager with data points to judge the efficacy of their choices. First, the scoreboard displays the "Projected Profit." This is, essentially, the profitability of the project if the currently selected choices were actually made. It accounts for all past choices (which cannot be changed) and all future ones (which can be). This is powerful, because it focuses the students on what is at stake: their profit. On the other hand, some choices that save money might also decrease quality. The scoreboard includes a "Litigation Potential" output, which quantifies this risk to the manager and may cause them to reconsider certain decisions. The dashboard also displays traditional earned value analysis metrics to help the CM assess performance. The Cost Performance Index indicates how efficiently they are spending money, both for the last period and cumulatively. 
The Schedule Performance Index shows how close they are to their planned schedule of values. The Estimate At Completion (EAC) predicts the final cost of the project if the CM were to continue spending money at the current rate. Examples are shown in Figure 4.

\begin{tabular}{|c|c|c|c|c|c|}
\hline \begin{tabular}{|l|}
$\begin{array}{l}\text { Projected } \\
\text { Profit }\end{array}$ \\
\end{tabular} & $\$ 5,121$ & & $\mathrm{CPI}$ & SPI & EAC \\
\hline \begin{tabular}{|l|} 
Projected \\
Profit \% \\
\end{tabular} & $5.8 \%$ & $\begin{array}{c}\text { Last } \\
\text { Period }\end{array}$ & 1.25 & 1.67 & \\
\hline \begin{tabular}{|l|} 
Litigation \\
Potential
\end{tabular} & $17 \%$ & Cumulative & 0.67 & 1.00 & $\$ 124,704$ \\
\hline
\end{tabular}

Figure 4: Project Imperium Performance Indices

Once each month begins, all levers are locked, and the CM must live with the consequences of their decisions, good or bad. The outputs are also displayed graphically in two charts. First, the "Account Balance" chart (Figure 5) is essentially the balance of their line of credit. In gray, it shows what they planned to spend and in blue, the CM can see how closely they are to that plan. The red vertical line indicates we are currently in Month 3 . This means that to the right of that red line is what the projected balance will be if the rest of the project plays out as the CM expects. Notice the blue line ends with an account balance of $\$ 5121$, which matches the "Projected Profit" output above.

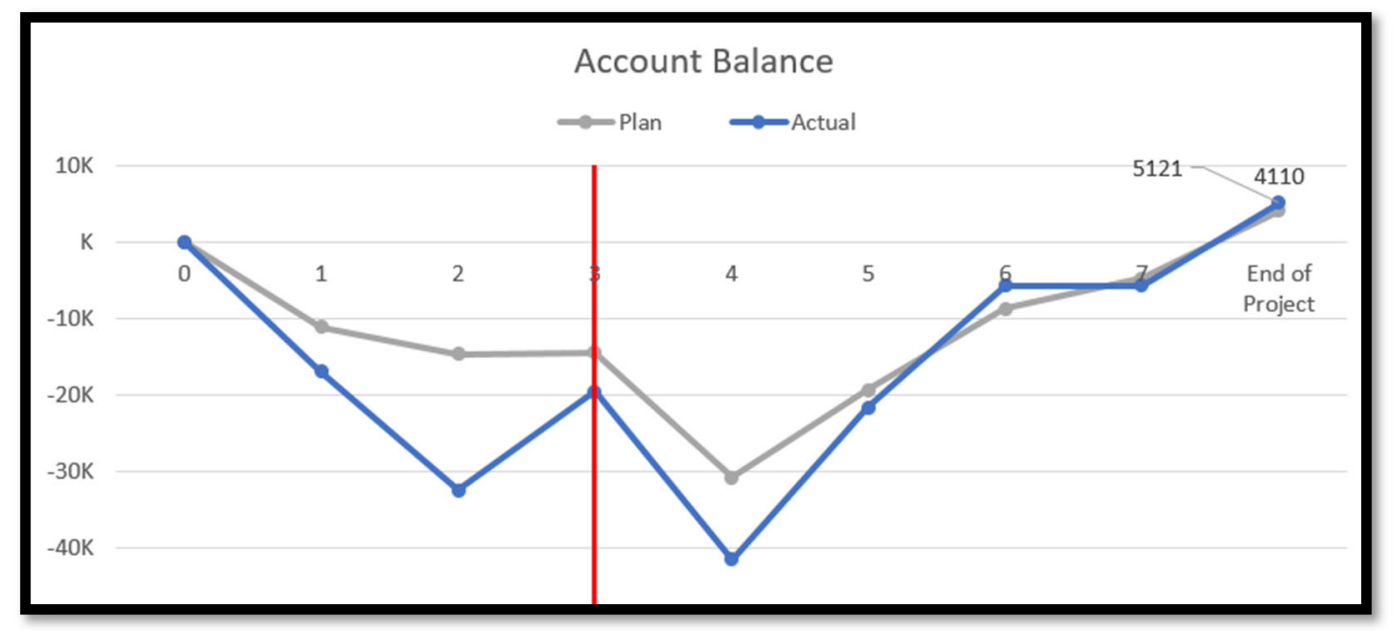

Figure 5: Account Balance display

In addition, the EVA graph (Figure 6) is particularly useful. The horizontal orange line represents the contract value; students should view this as a ceiling they should not cross. Again, we are currently in Month 3, so the user can see how their Schedule and Cost Variance has fluctuated over the first two completed months. In this case, it appears the team has spent more than planned in both months while earning the value they planned by the end of the second month, despite a poor performance in Month 1 . The dashed yellow line serves as a prediction linking past to future performance. Notice the EAC matches the Scoreboard and the dashed line highlights that if this current spending rate continues, the team will end up far over budget. Note that these two graphs complement each other. The larger-than-planned deficits in the account 
balance for Months 1 and 2 match the Actual Cost (yellow) curve on the EVA chart. As the exercise progresses these charts grow and change with the CMs decisions and actual work in place.

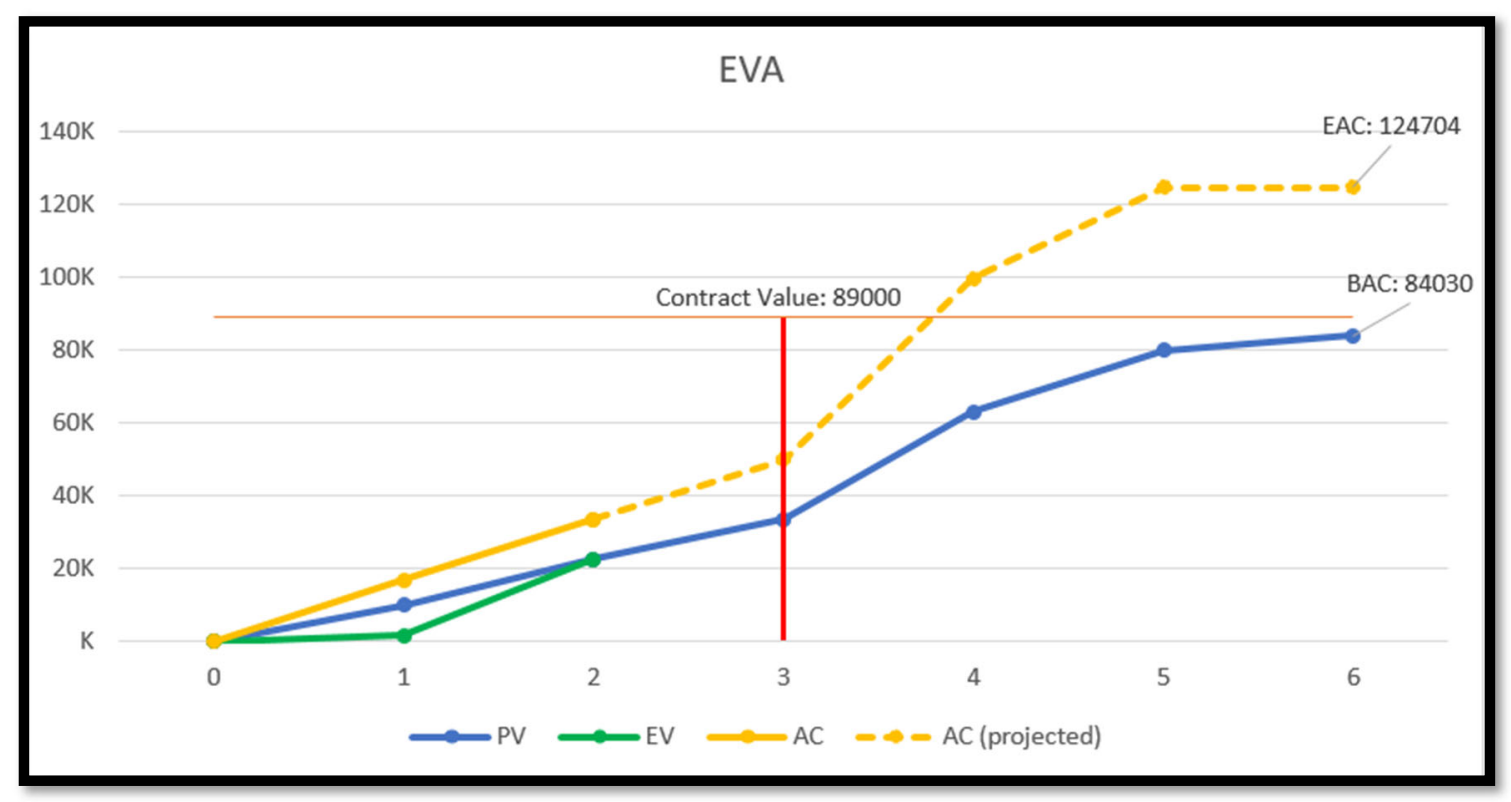

Figure 6: Earned Value Analysis

\section{Construction}

After loading their dashboards, teams mobilize to the construction sites. This event is intentionally not held in the classroom where the course is taught. This replicates the conditions a contractor might experience building somewhere they are unfamiliar. Construction occurs over the course of three lessons; in each lesson, two 10-minute months are executed.

\section{Materials}

Teams must develop a plan for when they will need specific material types. It is important to properly manage materials on site. They are encouraged to "build what you buy." Therefore, they must decide beforehand what materials they'll need for the following month. They can only have the materials they requested. Teams are charged a storage fee for any unused materials at the end of each month. This is quickly calculated by weighing the KNEX pieces and assessing a $\$ 2 /$ gram fee. This replicates material management challenges contractors face on projects; there is not an unlimited amount of space to stage materials on site. Remember, teams do have the option of express ordering materials in case they underestimated what they could complete. CMs quickly realize that idle labor is expensive. The dashboard allows them to quickly decide the cost-benefit of paying the $50 \%$ mark-up for additional materials in order to keep their labor crews working.

\section{Injects}

Despite our best efforts, classroom exercises typically fall far short of real world experiences. Project Imperium attempts to introduce more realism by adding an element of chance to the construction project. During Months 2 and 3 all teams experience an unexpected event or an inject. At a specific moment in the month, the instructor halts construction and spins the Wheel 
of Misfortune, which includes owner-caused delays, contractor-caused delays and Acts of Nature. All of the injects are entirely plausible occurrences: weather delays, permitting issues, unforeseen site conditions, archaeological discoveries and more. These events occur randomly and unexpected. The only commonality is everyone will experience a delaying event in the same month to ensure all teams are affected, generally, the same. These injects serve several purposes. First, is vividly illustrates to the managers that "no plan survives first contact." There are many things outside of the manager's control that they cannot avoid, but must be prepared to mitigate. In addition, they may result in litigation, depending on the cause. It is important for managers to take note of what happened, when it happened and for how long. Indeed, them may be able to file a justifiable claim to seek financial compensation or recoup lost time. It also highlights the important practice of contingency planning. Many teams will create very aggressive schedules without any buffers. They sacrifice flexibility for speed.

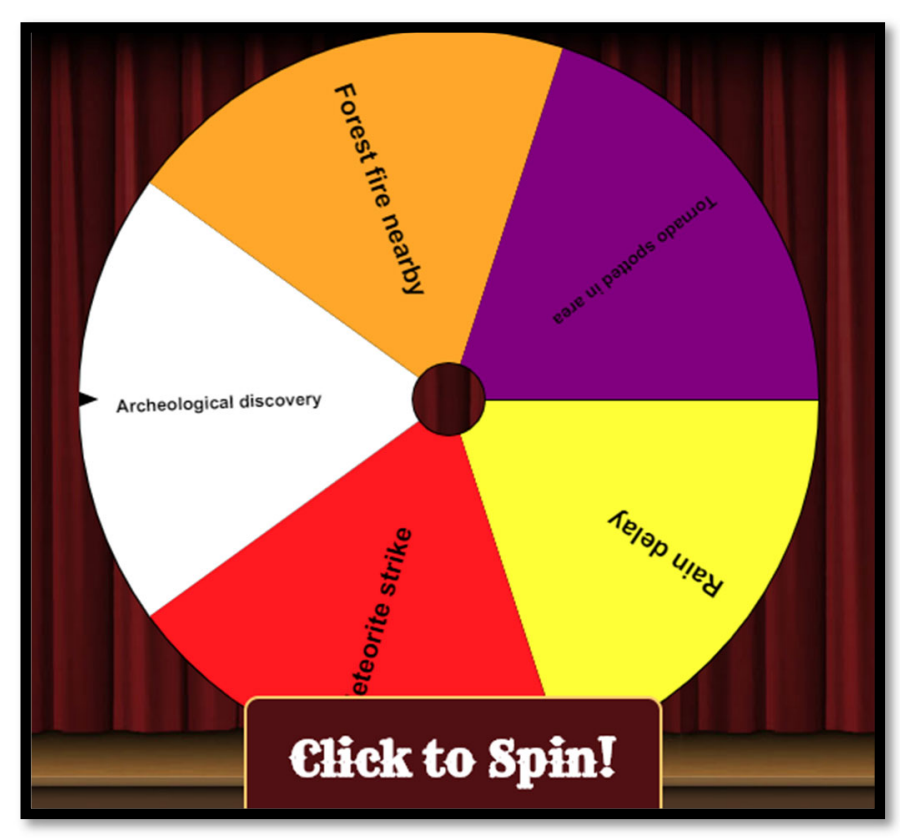

Figure 7: Wheel of Misfortune

Teams complete a construction report at the end of each month (10-minute build period). The project managers review their Gantt Charts and discuss what work was completed with the owner's representative (the instructor) to assess earned value each month. Project managers use the construction reports, as shown in Figure 8, to request payment and assess their team's performance using EVA. Project managers also use time between construction periods to decide whether they should make any changes to their plan, such as using additional or low-quality labor, working overtime, and/or using low-quality material (the "levers" previously discussed). 


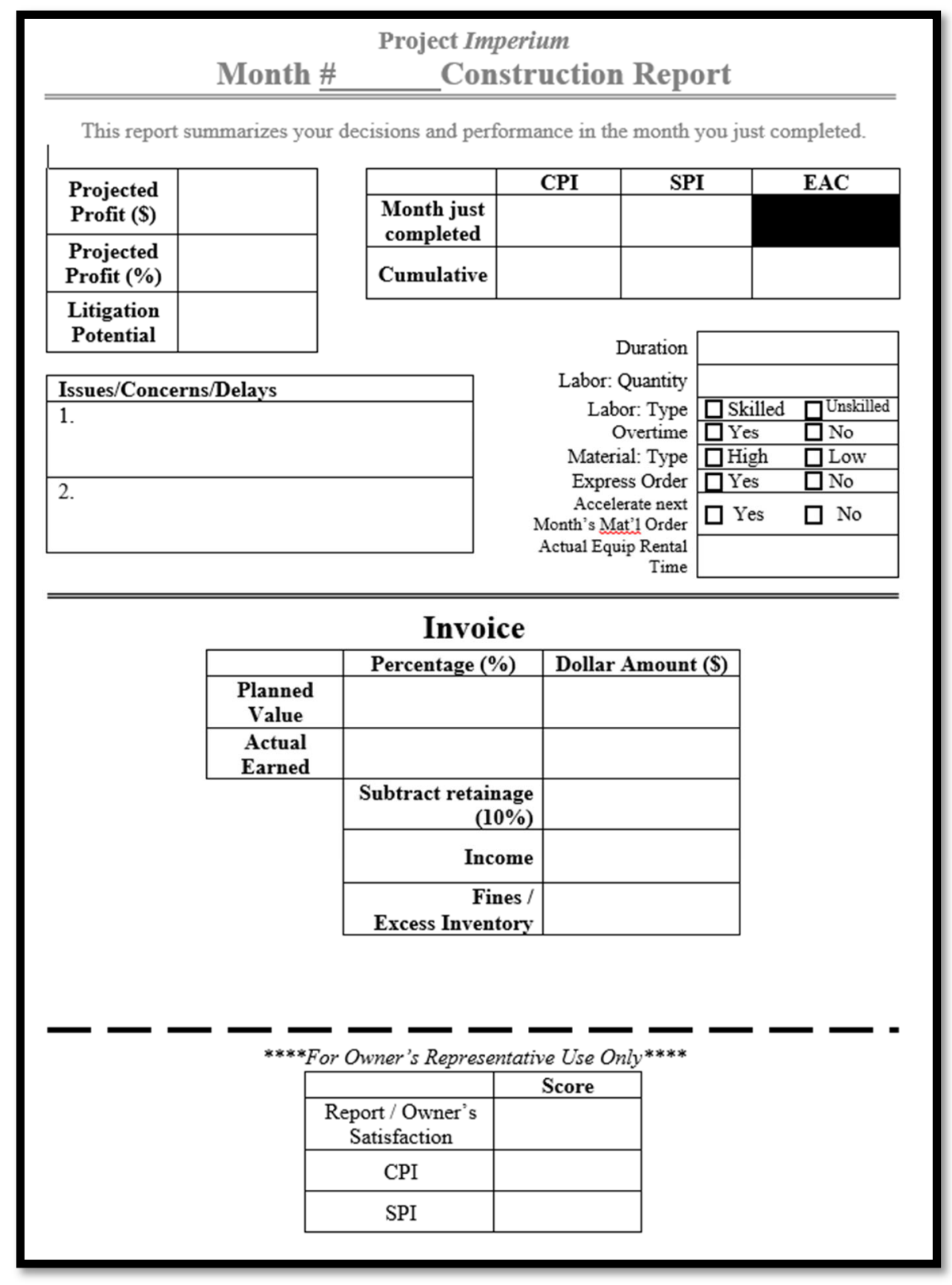

Figure 8: Construction Report

Teams are graded each month based on three elements of their performance, shown on the bottom of Figure 8. The owner's satisfaction score is based upon how well the CM communicated the team's progress and associated earned value, and the accuracy of the report itself. The CPI and SPI scores are related to the team's baseline. At the end of each month, teams can see where they stand compared to the other teams using the Cost Schedule Index, which is the product of the CPI and SPI. Overall assessment is based on the team's performance throughout the exercise.

After the project is completed, we discuss claims and dispute resolution in class. The following lesson, each team can make one claim against the owner in court. One of the injects from the "Wheel of Misfortune" was the owner's responsibility according to the contract. If the team 
makes a valid claim that is supported by evidence and their contract, they can earn a few bonus points for the exercise. While this exercise is a lot of fun, it does provide an opportunity for students to recognize the importance of understanding the terms of a contract, documenting actions that take place, and to communicate effectively.

Overall, we have found Project Imperium provides students with a simulated construction experience in which they can plan, execute, monitor, and control a project. The feedback from students has been very positive, and we have had several former students contact us to say the knowledge they gained from this exercise was one of the most valuable things they learned while in school and how it has helped them provide immediate added value in their current job. 